Volume 10, No.1, January - February 2021

International Journal of Advanced Trends in Computer Science and Engineering

Available Online at http://www.warse.org/IJATCSE/static/pdf/file/ijatcse621012021.pdf

https://doi.org/10.30534/ijatcse/2021/621012021

\title{
Performance Analysis of Analog Passive Detectors in Target Tracking Wireless Sensor Networks
}

\author{
Nilima Zade ${ }^{1}$, Dr. Deepa Parasar ${ }^{2}$ \\ ${ }^{1}$ Computer Science and Engineering, ASET, Amity University, Maharashtra, India, nilima.zade@ gmail.com \\ ${ }^{2}$ Computer Science and Engineering, ASET, Amity University, Maharashtra, India, dparasar@mum.amity.edu
}

\begin{abstract}
The development of surveillance systems for indoor and outdoor environments using currently available wireless sensor technology without violating privacy issues is a challenging task. Passive Infrared (PIR) detectors are suitable for such systems provided solutions to the technical limitations are implemented. In the proposed work, the development of a human tracking system using analogue PIR detectors and currently available wireless sensor technology is presented. Performance is evaluated by conducting real-time tests in different environmental scenarios. Analysis of experimental results of human sensing signals indicates that performance is affected by environmental parameters. These findings will be helpful for the researchers while implementing a real-time system in the field.
\end{abstract}

Keywords: Passive Infrared Detectors, Target Tracking, Wireless Sensor Networks, Surveillance System.

\section{INTRODUCTION}

Continuous monitoring of human being in indoor and outdoor environment without violating privacy issue is very important and challenging task in smart surveillance [1]. Developing cost effective, efficient system with the available off the shelf detectors for non-military applications is very difficult task. Active detectors such as visual camera, ultrasonic sensors, radar, microwave sensors, smart devices enabled with GPS technology provides accuracy in tracking with the trade off in increased power consumption and processing complexity [2]. The use of visual camera demands more battery power, processing power and large bandwidth for long distance communication. Passive detectors such as Passive Infrared sensors (PIR) can be used when optimization of power consumption and processing complexity is major objective to be achieved than the precise tracking accuracy.

The current research is extension of the work [3] using analogue PIR sensor. The research presented here is the analysis of analogue PIR sensor performance in tracking application with indoor and outdoor environment. The objective is to test and compare analogue and digital PIR sensor performance when used in target tracking application in indoor and outdoor environment. Issues and challenges encountered and its probable solutions developed while implementing target tracking WSN are presented.

The rest of the paper is organized as follows. Related work is described in section 2. Experimental setup, design and implementation is explained in section 3. In section 4 results along with analysis is mentioned. Conclusion is stated in section 5 .

\section{RELATED WORK}

In [4], [5], authors presented indoor localization using machine learning technologies based on the single analogue PIR sensor output. In [6], author proposed PIR based indoor localization using overlapped sensing area due to multiple nodes. In [7], author proposed geometric algebra approach using geographic sensor network for indoor localization. In [8], author used the multiple overlap Fields of Vision (FOV) of nodes with analogue PIR sensor. Most of localization techniques developed using passive sensor needs high processing power which leads to the restriction on utilization of these technique to indoor localization only. In $[9,10]$ developed a system for outdoor localization using multiple analogue PIR sensor. To meet the requirement of high power, solar powered batteries are installed. The application specific analogue hardware implementations are not flexible, so are difficult to adopt as implementation for generalized application to outdoor environment. In [11] target tracking with binary PIR sensor is presented. In the previous work presented in [12,13], issues and challenges while implementing tracking system with binary PIR sensor has been presented. Researchers significant contribution indicates that such implementations are application specific and has scope in the field.

\section{EXPERIMENTAL SETUP}

This research aims to test analogue PIR sensor for motion detection in indoor and outdoor environment. Custom made 
system has been designed for experimenting. Following subsection illustrates the design and implementation details.

\subsection{Design of Wireless Sensor Node}

Each wireless sensor node consists of 2 analogue PIR sensors (IRA-S210ST01), signal conditioning circuit, microcontroller (ATMEGA 328P), Zigbee communication module, humidity sensor, photodiode and a battery. Figure 1 shows the block diagram of single node and Figure 2 shows Block diagram of signal conditioning circuit. To strengthen the incoming infrared signal, Lens (IML-0685/0688) has been used. To differentiate different class of targets, that is target with more height (adult human) and target with less height (child /animal), two PIR sensors are used in a node. PIR sensor output is in the range of microvolts, so to enhance signal level each PIR sensor is connected to an Op-amp so as to form amplifier band pass filter with high input impedance. PIR output is amplified in two stages as shown in figure 3. In first stage PIR output is amplified by removing DC component using coupling capacitor between PIR sensor and Op-amp. It amplifies the signal for a gain of $37451 \mathrm{~dB}$. The cut-off frequencies for the band-pass filter are set to $0.1 \mathrm{~Hz}$ to $12 \mathrm{~Hz}$, which is enough to detect human/animal motion. The Mcp606 has a unity gain bandwidth of $155 \mathrm{~Hz}$, so the maximum bandwidth is limited to $414 \mathrm{~Hz}$. In second stage, the output of stage one Op-amp is passed through summing amplifier. The gain of summing amplifier is $6736 \mathrm{~dB}$ with cut-off frequencies for low pass filter is set as $0.1 \mathrm{~Hz}$ to $13 \mathrm{~Hz}$. MCP6042 has the unity gain bandwidth of $14 \mathrm{~Hz}$, therefore the bandwidth is limited to $206 \mathrm{~Hz}$. After second stage the signal is fed to the window comparator which converters the analogue signal to digital signal using threshold set by reference resistors. Such a design enables to separation of motion signal from noise. The digital signal is used as an interrupt to the microcontroller when motion has been detected by PIR sensor. ADC reference voltage is created by using a voltage divider and voltage follower circuit. Figure 4 shows the image of actual node developed.

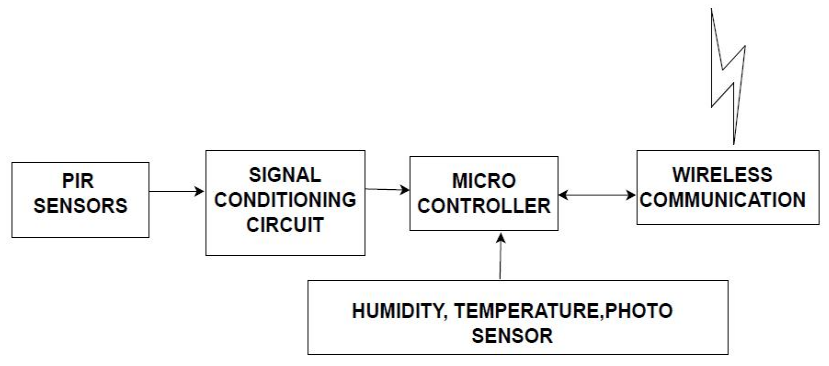

Figure 1: Complete System's Block Diagram

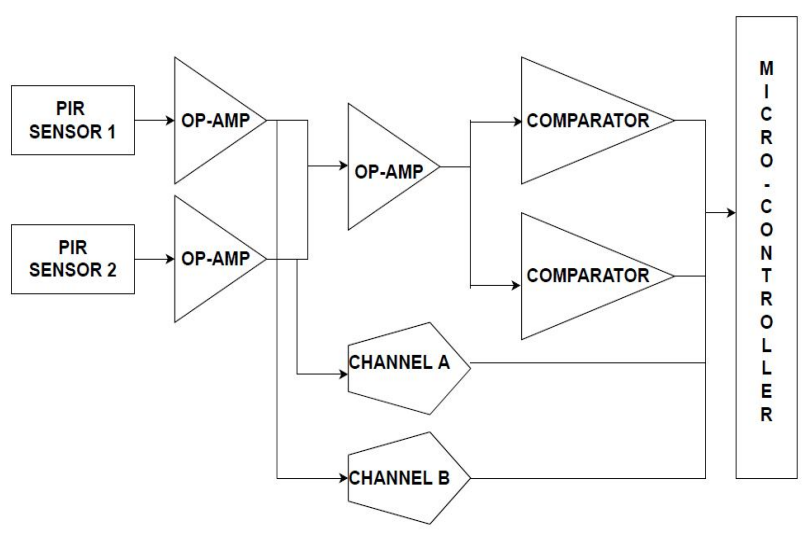

Figure 2: Block Diagram of Signal Conditioning Circuit

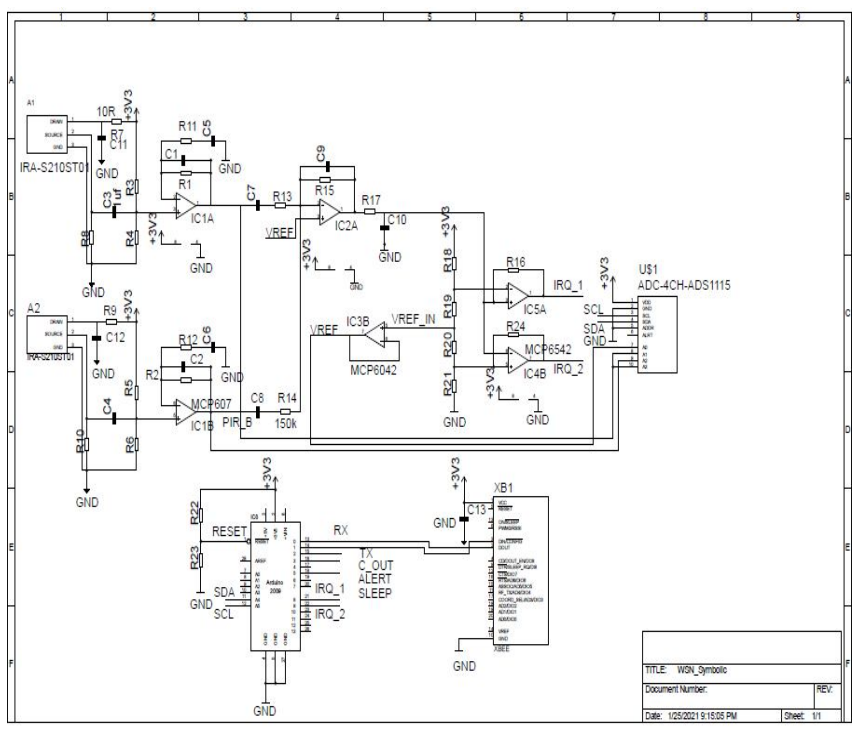

Figure 3: Circuit Diagram of Signal Conditioning Circuit

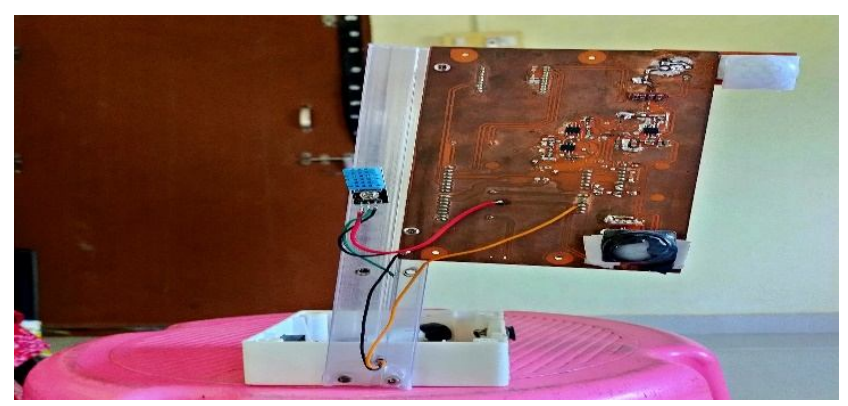

Figure 4: Developed Wireless Sensor Node 


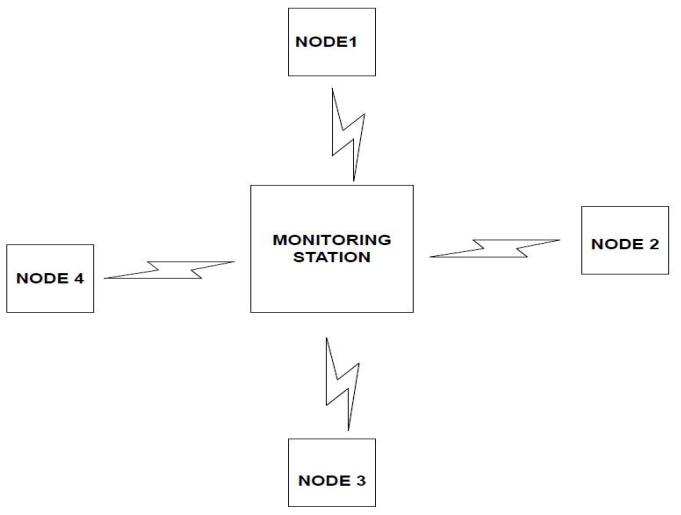

Figure 5: Network Setup

Mesh network topology is used for communication between wireless sensor nodes and coordinator. Network is created through Zigbee coordinator and other nodes join the network. XCTU application software is used to create the network. Figure 5 shows the block diagram with 4 sensor nodes with a coordinator.

\subsection{Issues and Challenges Faced During Development Process and Its Solution}

Many issues have been encountered while working on implementation of the system with the analogue PIR sensor in indoor and outdoor environment. False detection problem in both the environment was predominant due to ambient temperature, humidity, target speed, motion direction, distance from sensor, size of moving body. To reduce the rate of false detection humidity sensor, temperature sensor, and photo detectors are incorporated in the design. False triggering problem of window comparator has been overcome by implementing hysteresis concept along with $\mathrm{RC}$ filter at output stage of window comparator. Sensor elements are very sensitive to radiation over a wide range of infrared signal. To limit incoming radiation to $8 \mu \mathrm{m}$ to $14 \mu \mathrm{m}$ range, a filter window is applied. The system is designed to have $2 \mathrm{sec}$ delay time between two consecutive detections. System takes $30 \mathrm{sec}$ to $40 \mathrm{sec}$ time to stabilize at initial boot-up phase. To get proper output signal $\mathrm{V}_{\text {ref }}$ has been adjusted to $1.6 \mathrm{mv}$.

\section{EXPERIMENTAL RESULTS AND DISCUSSION}

PIR sensor node is tested, and based on behavior and performance of wireless PIR sensor node and sensor output data, tracking algorithm is designed. Multiple runs are conducted by varying various parameters in indoor and outdoor environment. Figure 6 shows images of actual testing scenario. Not only temperature but also parameters like humidity, wind speed, node placement location affects the performance of the node and same hardware system may behave differently for these parameter variations. Therefore, three time zones, morning afternoon and evening have been considered while testing sensor signal the system. Figure 7 shows the sensor output for human detection with different speed at different time zone in indoor as well as outdoor environment. The table 1 shows the sensing and communication power consumption of the system. As per the working principle of the sensor, radial motion towards the sensor is difficult to identify but while testing satisfactory results are achieved. While testing it is observed that, when target is within $1 \mathrm{~m}$ distance from node, whatever may be the height of the node from ground, it is difficult to detect the target. To overcome this problem either use of multiple nodes with completely overlapped sensing area can be implemented or spot lens PIR sensor can be used. This problem can be resolved by placing four nodes covering all the area. Total 286 tests conducted in all three time zones that is for each time zone and each environment 66 test have been conducted and signals are recorded. Figure 8 and figure 9 shows the output signal received for 3 sample tests in each time zone and each environment. As the target goes away from the sensor, the amplitude of signal reduces and width of signal increases. Figure 10 to 12 represents average of test results in each time zone and each environment. It is clearly indicated from graphs mentioned in the figure 10 to 12 that behavior of sensor is affected and changes when tested for indoor and outdoor environment. In an outdoor environment temperature difference between target and environment is less compared to indoor environment. Due to this the node generates output signal with less amplitude in outdoor environment than indoor environment. When the testing is done in morning time, rate of false triggers has been increased and could not get expected results. The reason behind is that, during this time zone the difference between environment temperature and target is less in both the environments. Figure 12 indicates that during this time zone, the performance of the node is degraded due to technical limitation. Table 2 shows the percentage of false reading when system is tested in afternoon and evening time zone for outdoor and indoor environment. Table 3 indicates false alarm rate for all test scenarios and it is found that in morning time is increased above 50 percent due the reason mentioned above. It has been observed that when multiple targets cross the sensing area within detection delay time, they are not detectable. This is a major technical limitation. Also signal interference occurs due to multiple targets crossing the area at a time. To overcome above technical limitations, complex and efficient tracking algorithm is needed.

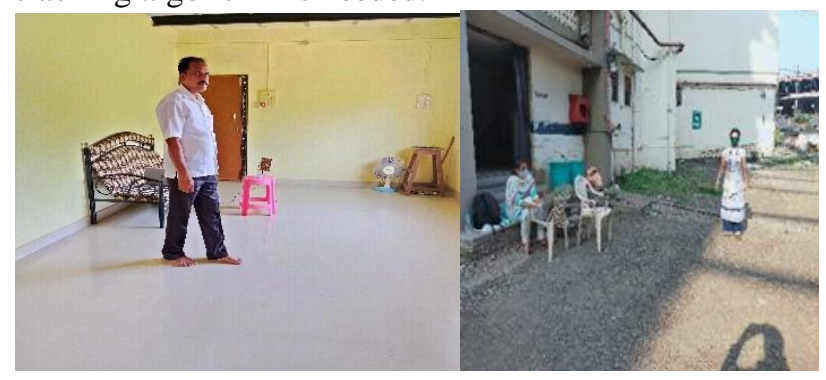

Figure 6: Indoor and outdoor testing 


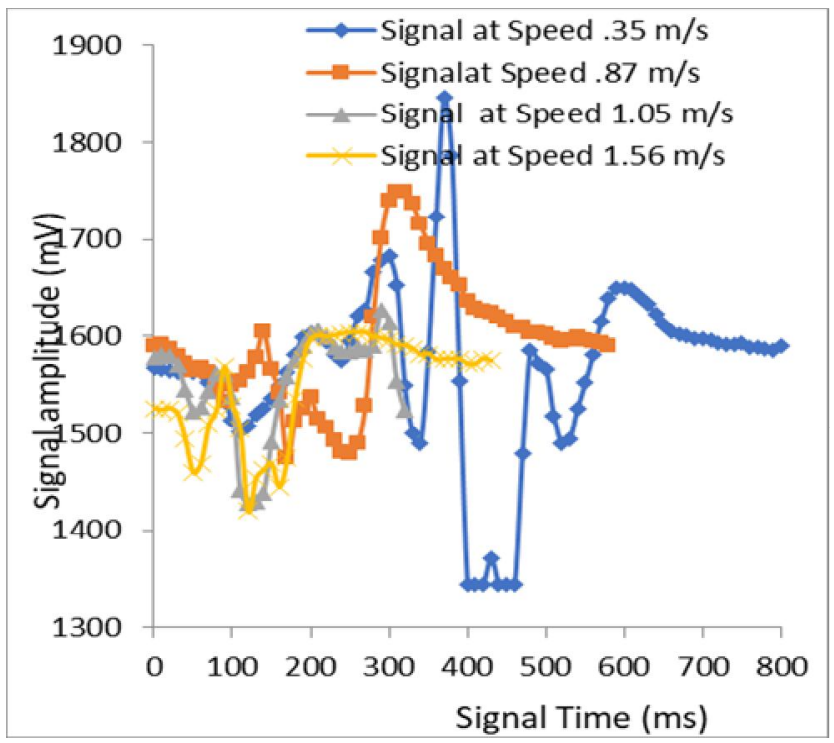

Figure 7: PIR output signal when tested for different target speed

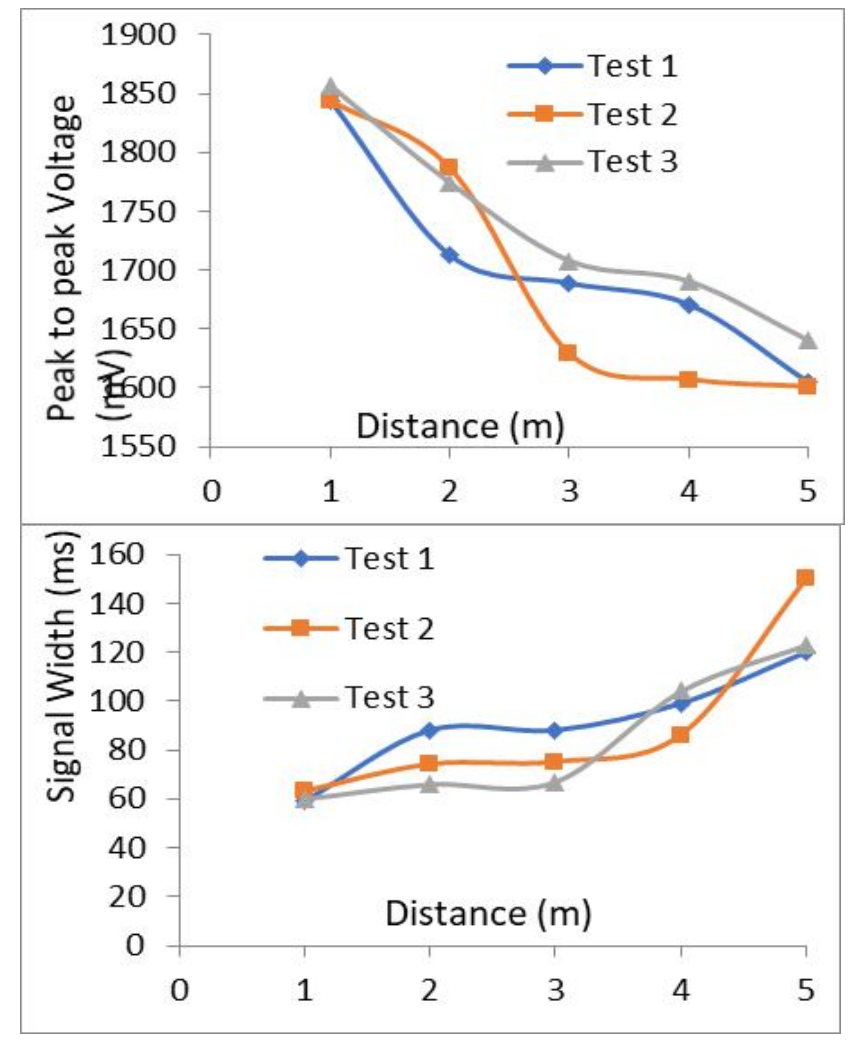

Figure 8: PIR output voltage vs target distance from node and PIR output signal width vs target distance from node in outdoor Afternoon Testing.

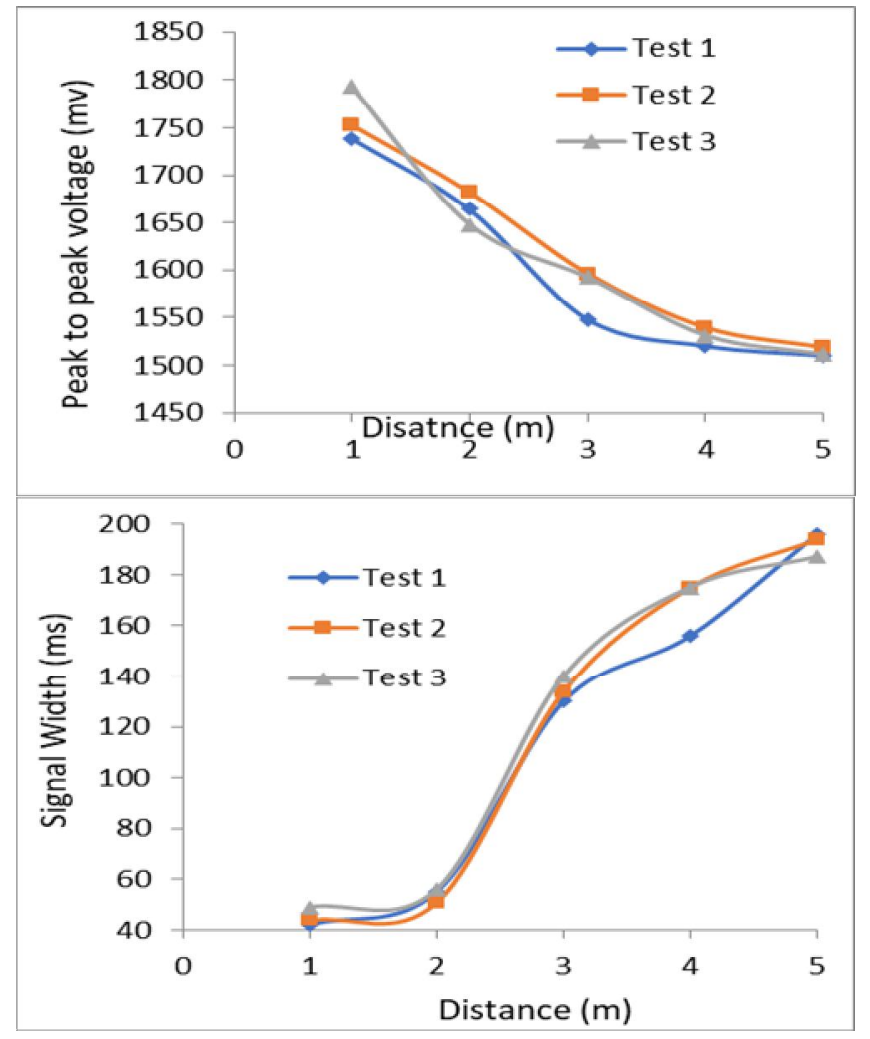

Figure 9: PIR output voltage vs target distance from node and PIR output signal width vs target distance from node in Indoor Afternoon Testing

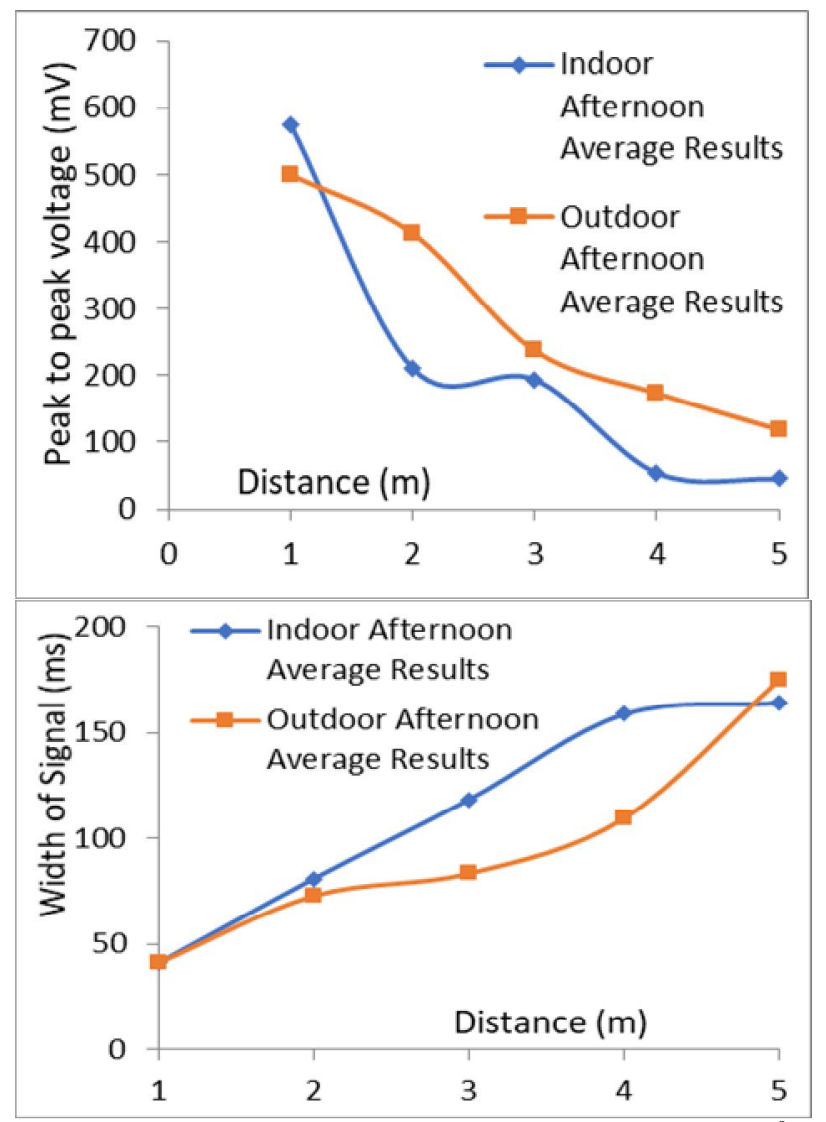

Figure 10: Average Afternoon test results (Indoor Temp. $26^{\circ} \mathrm{C}$ and Outdoor $29^{0}$ ) 
Table 1: Sensing and communication Power consumption of single sensor node

\begin{tabular}{|l|l|l|l|}
\hline Test Condition & $\begin{array}{l}\text { Mode of } \\
\text { operation }\end{array}$ & Voltage & Current \\
\hline $\begin{array}{l}\text { Microcontroller } \\
\text { without sensor } \\
\text { without Zigbee } \\
\text { (S2C) }\end{array}$ & Sleep & $3.3 \mathrm{~V}$ & $\begin{array}{l}19.7 \\
\mathrm{~mA}\end{array}$ \\
\hline $\begin{array}{l}\text { Microcontroller } \\
\text { without sensor } \\
\text { without Zigbee } \\
\text { (S2C) }\end{array}$ & Active & $3.3 \mathrm{~V}$ & $28 \mathrm{~mA}$ \\
\hline $\begin{array}{l}\text { Microcontroller } \\
\text { with sensor without } \\
\text { Zigbee (S2C) }\end{array}$ & $\begin{array}{l}\text { Microcontroller } \\
\text { is in sleep mode } \\
\text { and sensor is } \\
\text { sensing but } \\
\text { object is not in } \\
\text { range. }\end{array}$ & $3.3 \mathrm{~V}$ & $\begin{array}{l}19.804 \\
\mathrm{~mA}\end{array}$ \\
\hline $\begin{array}{l}\text { Microcontroller } \\
\text { with sensor with } \\
\text { Zigbee (S2C) }\end{array}$ & $\begin{array}{l}\text { Object is in } \\
\text { sensing range. }\end{array}$ & $3.3 \mathrm{~V}$ & $58 \mathrm{~mA}$ \\
\hline
\end{tabular}

Table 2: False alarm rate for afternoon and evening testing scenario

\begin{tabular}{|c|c|c|l|l|}
\hline $\begin{array}{l}\text { Total } \\
\text { Readings }\end{array}$ & $\begin{array}{l}\text { Correctly } \\
\text { detected }\end{array}$ & Missed & $\begin{array}{l}\text { False } \\
\text { alarm }\end{array}$ & $\begin{array}{l}\% \text { False } \\
\text { Alarms } \\
\text { rate }\end{array}$ \\
\hline 220 & 166 & 03 & 51 & $28.18 \%$ \\
\hline
\end{tabular}

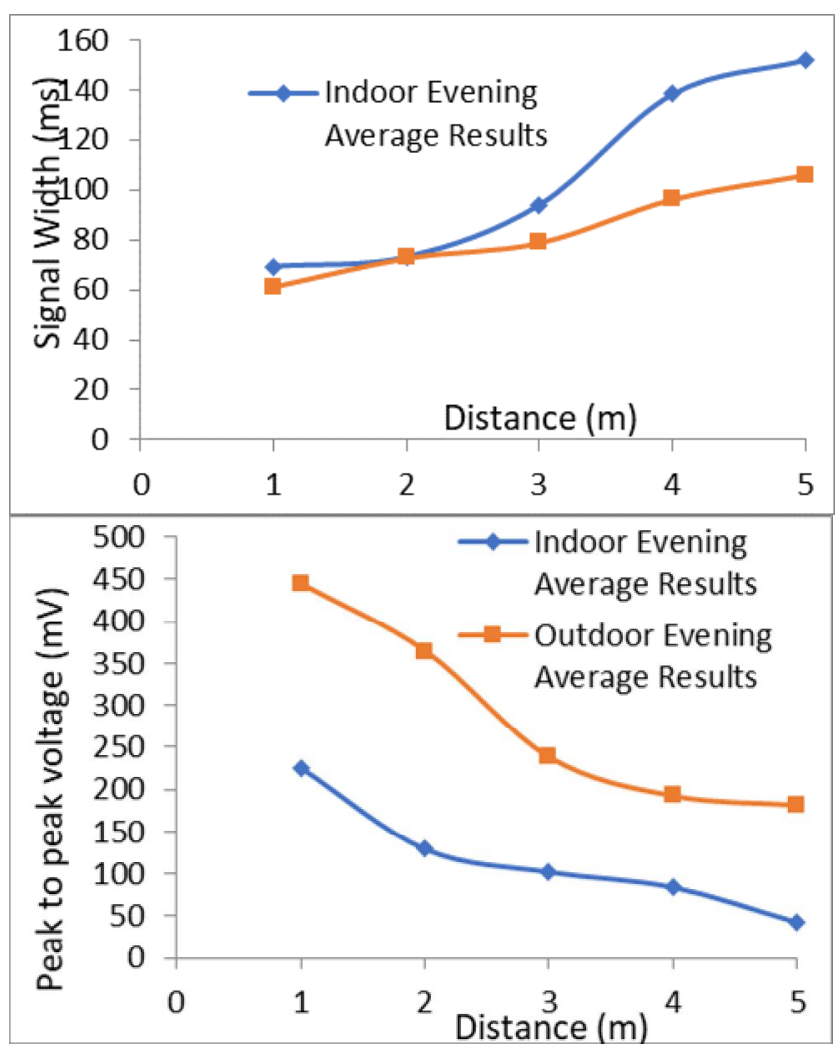

Figure 11: Average Evening test results (Indoor Temp. $24^{\circ} \mathrm{C}$ and Outdoor $27^{0} \mathrm{C}$ )
Table 3: False alarm rate for each test scenario

\begin{tabular}{|l|l|}
\hline$\%$ False Alarms rate & Time zone of test \\
\hline $28.18 \%$ & Indoor Afternoon \\
\hline $16.36 \%$ & Indoor Evening \\
\hline $21.81 \%$ & Outdoor Afternoon \\
\hline $30.16 \%$ & Outdoor Afternoon \\
\hline $50 \%$ & Indoor Morning \\
\hline $54 \%$ & Outdoor Morning \\
\hline
\end{tabular}

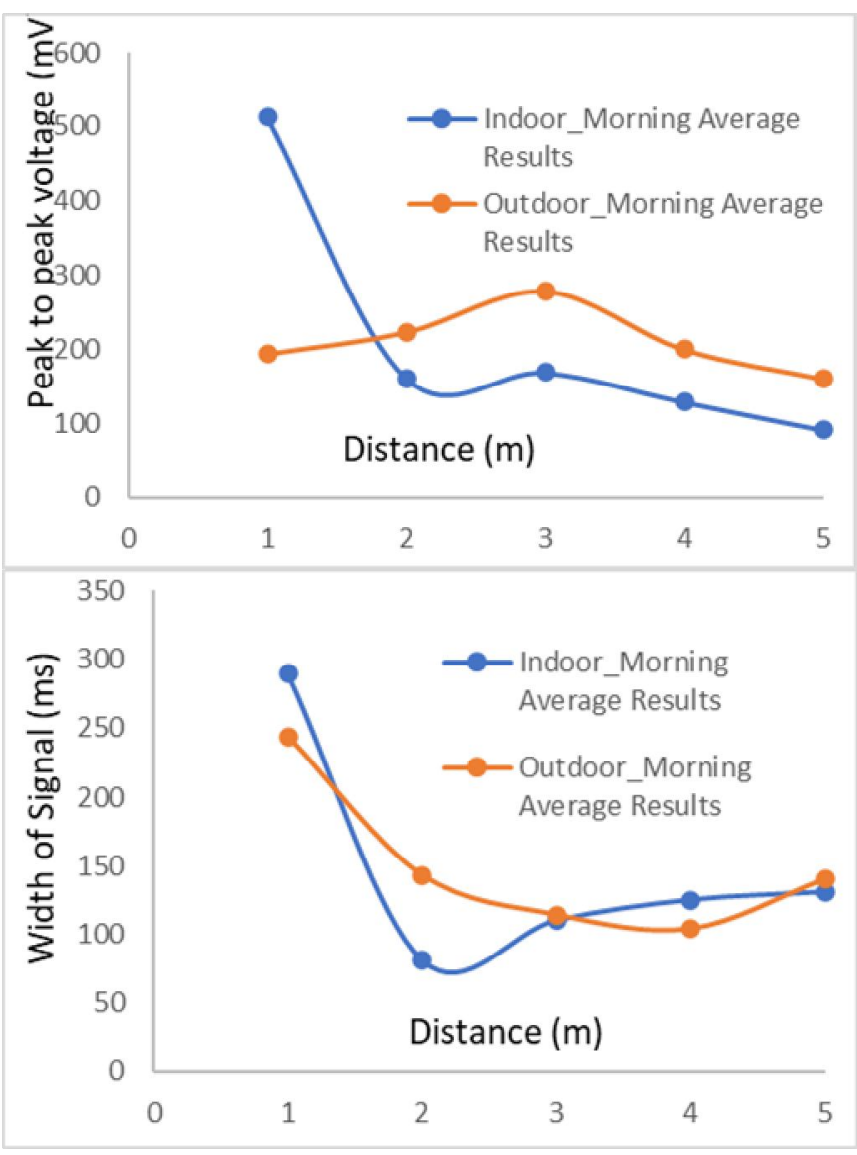

Figure 12: Average Morning test result (Indoor Temp. $21^{0} \mathrm{C}$ and Outdoor $20^{\circ}$ to $21^{0}$ )

\section{CONCLUSION}

The paper presents the analysis of performance of analogue PIR sensing, human tracking system in indoor and outdoor environment. A wireless sensor node with analogue PIR sensor has been developed using off the shelf hardware components. Real time experimental tests have been conducted to analyze the analogue signal and sensing behaviors. The effect of environmental parameters on the performance has been analyzed and discussed. Technical limitations have been analyzed and possible solutions have been presented. As per findings based on this work, different reliable localization algorithm for indoor and outdoor environment with same hardware setup will be implemented in the future work. 


\section{REFERENCES}

1. Nilima Zade, Shubhada Deshpande, R Kamatchi, A Review on Object Tracking Wireless Sensor Network an Approach for Smart Surveillance, in New Trends in Computational Vision and Bio-inspired Computing, Springer International Publishing. 2020 978-3-030-41862-5, pp. 909-921.

2. Nilima Zade, Shubhada Deshpande, D Sita, Investigative Analysis of Suboptimal Filter for State Estimation in Object Tracking Wireless Sensor Network in IEEE Sensors Letters, vol. 4, no. 10, pp. 1-4, Oct. 2020.

3. Nilima Zade, Shubhada Deshpande, D Sit, Analysis of Passive Infrared Detector for Target Detection in an IOT Based Outdoor Environment, in proc. IC-RACT India. 2020, https://ssrn.com/abstract=3696476

4. Hiren Gami, Movement Direction and Distance Classification Using a Single PIR, in IEEE Sensors Letters vol. 2, no. 1, pp. 1-4, March. 2018.

5. Jaeseok Yun, Sang-Shin Lee., Human Movement Detection and Identification using Pyroelectric Infrared Sensors, in Sensors, 14(5), 8057-8081, 2014.

6. Sujay Narayana and T. V. Prabhakar, PIR Sensors: Characterization and Novel Localization Technique, in Proc. of the 14th International Conference on Information Processing in Sensor, April 2015. doi.org/10.1145/2737095.2742561

7. Zhaoyuan Yu, Linwang Yuan, Wen Luo, Linyao Feng and Guonian Lv, Spatio-Temporal Constrained Human Trajectory Generation from the PIR Motion Detector Sensor Network Data: A Geometric Algebra Approach, in Sensors, 16, 43, 2016, doi:10.3390/s16010043

8. Zhiqiang Zhang, Xuebin Gao and Jit Biswas, Jian Kang $\mathrm{Wu}$, Moving Targets Detection and Localization in Passive Infrared Sensor Networks, in 10th International Conference on Information Fusion, Quebec, QC, Canada, 2007 pp 1-6. doi: 10.1109/ICIF.2007.4408178

9. Tarun Choubisa, R. Upadrashta, S. Panchal, et al. Challenges in Developing and Deploying a PIR Sensor-Based Intrusion Classification System for an Outdoor Environment, in IEEE 11th Int. Workshop on Practical Issues in Building Sensor Network Applicat. SensApp., 2016, pp 148-155.

10. Raviteja U., Tarun C., A. Praneeth, et al. Animation and Chirplet-Based Development of a PIR Sensor Array for Intruder Classification in an Outdoor Environment, in arXivPrePrintarXiv: 1604.03829,2016.

11. Alma Oracevic, Serkan Akbas, Suat Ozdemir, Secure and reliable object tracking in wireless sensor networks, in Computers \& Security, Vol 70,2017, pp 307-318, doi.org/10.1016/j.cose.2017.06.009.

12. Nilima Zade, Shubhada Deshpande, R Kamatchi, Target Tracking Based on Approximate Localization
Technique in Deterministic Directional Passive Sensor Network, in Springer Journal of Ambient Intelligence and Humanized Computing (AIHC), January 2021. DoI10.1007/s 12652-020-02783-5

13. Nilima Zade, Shubhada Deshpande, D Sita, Approximate Localization of Non Cooperative Moving Target in Outdoor Deterministic Directional Passive Sensor Networks, will be available in Springer lecture notes Networks and Systems, https://doi.org/10.1007/978-981-33-4073-2_21 